\title{
Corrosion Inhibition Effect of Cefotaxime Sodium on Mild Steel in Acidic and Neutral Media
}

\author{
Bilan Lin ${ }^{1,2, *}$, Shiwei Zheng ${ }^{1}$, Jiapo Liu ${ }^{1}$, and Yuye Xu ${ }^{3}$ \\ ${ }^{1}$ School of Material Science and Engineering, Xiamen University of Technology, Xiamen 361024, \\ China \\ ${ }^{2}$ Key Laboratory of Functional Materials and Applications of Fujian Province, Xiamen 361024, China \\ ${ }^{3}$ College of Civil Engineering, Huaqiao University, Xiamen, Fujian 361021, China \\ *E-mail: linbilan@xmut.edu.cn
}

doi: $10.20964 / 2020.03 .73$

Received: 15 November 2019 / Accepted: 5 January 2020 / Published: 10 February 2020

\begin{abstract}
The expired antibiotic cefotaxime sodium $(\mathrm{CEF})$ was investigated as a corrosion inhibitor for mild steel in $1.0 \mathrm{~mol} / \mathrm{L} \mathrm{H}_{3} \mathrm{PO}_{4}$ and $0.6 \mathrm{~mol} / \mathrm{L} \mathrm{NaCl}$ solutions. Corrosion behavior was studied via the open circuit potential (OCP), potentiodynamic polarization curves, electrochemical impedance spectroscopy (EIS), and scanning electron microscopy. Furthermore, the adsorption mechanism was investigated. In $\mathrm{H}_{3} \mathrm{PO}_{4}$ solution, the adsorption-desorption equilibrium of CEF molecule was reached rapidly. CEF acted as a mixed corrosion inhibitor. CEF adsorption obeyed Langmuir isotherm model and could be attributed primarily to chemical adsorption. The optimal concentration of CEF was in the range of 0.5 $\mathrm{m} \mathrm{mol} / \mathrm{L}$ and $0.8 \mathrm{~m} \mathrm{~mol} / \mathrm{L}$ and the geometric coverage was about 0.87 . A continuous thin film formed and the double-layer capacitance decreased. CEF offered effective long-term corrosion protection for mild steel in $\mathrm{H}_{3} \mathrm{PO}_{4}$ solution. However, the $\mathrm{CEF}$ adsorption-desorption equilibrium in $\mathrm{NaCl}$ solution was difficult. CEF could only slightly inhibit anodic corrosion. The CEF coverage was only 0.1. CEF provided almost no corrosion protection in the neutral $\mathrm{NaCl}$ solution. $\mathrm{CEF}$ did not change the corrosion mechanism of mild steel. The contrast inhibition efficiency between both solutions is directly related to the different corrosion mechanisms and the large quantity of chloride ions present in $\mathrm{NaCl}$ solution.
\end{abstract}

Keywords: Cefotaxime; Mild Steel; Corrosion; Electrochemical; Expired Drugs

\section{FULL TEXT}

(C) 2020 The Authors. Published by ESG (www.electrochemsci.org). This article is an open access article distributed under the terms and conditions of the Creative Commons Attribution license (http://creativecommons.org/licenses/by/4.0/). 